\title{
Análise Microbiológica de Batons de Uso Compartilhado na Cidade de Juazeiro do Norte-CE
}

\author{
Microbiological Analysis of Lipsticks for Shared Use in the City of Juazeiro do Norte-CE
}

\author{
Luana Romão Rodrigues*a; João Victor de Freitas Menezes ${ }^{\mathrm{a}}$; Dárcio Luiz de Sousa Júnior ${ }^{\mathrm{b}}$; Rafael de Carvalho Mendes ${ }^{\mathrm{c}}$ \\ anstituto de Ciência, Tecnologia e Qualidade, Programa de Pós-Graduação em Farmácia Clínica e Prescrição Farmacêutica. GO, Brasil. \\ bUniversidade Estadual do Cariri, Programa de Pós-Graduação Stricto Sensu em Química Biológica. CE, Brasil. \\ 'Faculdade de Medicina Estácio de Juazeiro de Nortes. CE, Brasil. \\ *E-mail: luanarrsm@gmail.com
}

\begin{abstract}
Resumo
A cosmetologia é a ciência que engloba e estuda os cosméticos, desde conceitos iniciais até a sua fabricação, tornando-se uma ciência multidisciplinar. Para garantia de um uso seguro e eficaz dos cosméticos é necessário a realização de análises para se conseguir um padrão de qualidade. Quando há indícios de contaminação por microrganismos no cosmético, diversos problemas podem ser encontrados, como a ocorrência de patologias específicas, causando altos riscos e complicações à saúde do usuário. O objetivo deste trabalho foi investigar qualitativamente através de análises microbiológicas a qualidade dos produtos cosméticos de maquiagem usados de forma compartilhada, utilizando amostras colhidas aleatoriamente em uma loja de varejo, que foi selecionada por ser de grande circulação, da cidade de Juazeiro do Norte, Ceará. Nesta pesquisa foram analisadas oito amostras coletadas durante o período de outubro e novembro de 2017 . As análises que foram realizadas seguiram a Farmacopeia brasileira. Como resultado obteve-se um percentual de 87,5 \% de contaminação microbiana, evidenciando a presença de Staphylococcus aureus, Escherichia coli, Enterococcus sp. e Pseudomonas aeruginosa, sendo que apenas uma das oito amostras analisadas mostrou-se adequada para uso seguindo os limites de aceitação microbiológicas permitidos por lei. Baseados nesses resultados foi possível concluir que o índice de contaminação das amostras de batons que são utilizadas de modo compartilhado são potencialmente maiores. Com isso, intensifica-se a necessidade de medidas que impeçam o compartilhamento dos produtos cosméticos, com a finalidade de diminuir o risco de uma infecção coletiva.
\end{abstract}

Palavras-chave: Cosméticos. Uso compartilhado. Contaminação.

\begin{abstract}
Cosmetology is the science that encompasses and studies cosmetics, from initial concepts to their manufacture, becoming a multidisciplinary science. To guarantee a safe and effective use of cosmetics it is necessary to carry out analyzes to achieve a quality standard. When there is evidence of contamination by microorganisms in the cosmetic, several problems can be found, such as the occurrence of specific pathologies, causing high risks and complications to the health of the user. The objective of this scientific work was to qualitatively investigate through microbiological analysis the quality of cosmetic makeup products used in a shared way, using samples collected randomly in a retail store, which was selected because it is of great circulation, in the city of Juazeiro do Norte, Ceará. In this research, eight (8) samples collected during the period of October and November 2017 were analyzed. The analyzes that were carried out followed the Brazilian Pharmacopoeia. As a result, a percentage of $87.5 \%$ of microbial contamination was obtained, showing the presence of Staphylococcus aureus, Escherichia coli, Enterococcus sp. and Pseudomonas aeruginosa, with only one of the eight samples analyzed being suitable for use following the limits of microbiological acceptance allowed by law. Based on these results it was possible to conclude that the contamination index of the lipstick samples that are used in a shared way are potentially higher. As a result, the need for measures to prevent the sharing of cosmetic products is intensified, in order to reduce the risk of a collective infection.
\end{abstract}

Keywords: Cosmetics. Shared Use. Contamination.

\section{Introdução}

A beleza de forma geral e mais especificamente aquela observada num primeiro contato. A beleza exterior é um parâmetro construído por meio de diversos produtos rotineiramente consumidos. Busca-se diariamente, com a utilização de cosméticos, uma melhora da aparência da pele, considerando ser esse o maior órgão corporal e que necessita de muitos e variados cuidados (MOTA et al., 2014).

A cosmetologia como ciência, engloba e estuda os cosméticos, desde conceitos iniciais até a sua fabricação, tornando-se uma ciência multidisciplinar. Os cosméticos constituem-se em preparações através de substâncias naturais ou sintéticas que tem como objetivo promover à limpeza, a perfumação, a alteração da aparência, e a inibição de odores corporais, seguindo a RDC $n^{\circ} 211$, de 14 de julho de 2005, que dispõe sobre as definições e classificações de produtos de higiene pessoal, cosméticos e perfumaria (BRASIL, 2005; BRANDÃO et al., 2015; MAEHATA, 2016).

Atualmente, a indústria de cosméticos é extremamente importante dentro da economia de grande parte dos países, dentre os quais se inclui o Brasil. Analisando os últimos índices disponíveis de produtos inclusos na categoria de cosméticos, detectou-se uma representação de aproximadamente $7,1 \%$ do consumo mundial de produtos de beleza por parte do Brasil, 
classificando-o como quarto colocado no ranking mundial, e quinto colocado na categoria de maquiagem, sendo o batom o produto mais comprado e consumido por mulheres no mundo (ABIHPEC, 2016; GALEMBECK; CSORDAS, 2011).

$\mathrm{O}$ batom é fabricado em formato de haste, acoplada em um estojo de recolher. Basicamente sua composição contém corantes, ceras, gorduras, misturas de óleos, como também a adição de perfumes e conservantes. São produtos dedicados a transformar a cor dos lábios, oferecendo-lhes uma nova tez, com ou sem reflexos e brilhos de cores variadas (MAEHATA, 2016; TAHAN, 2015).

Para que o batom seja avaliado e classificado como de boa qualidade é imprescindível possuir uma aplicação facilitada, com tom uniforme, alta aderência, resistência ao toque e a quebra, superfície suave, cor no lábio semelhante à apresentada no seu rótulo, manter a estabilidade no decorrer da sua vida útil, não sofrer influência térmica de armazenagem e da aplicação, não possuir sabor e/ou odor desagradáveis e não provocar irritação a mucosa (SÁ, 2016).

Para garantia de um uso seguro e eficaz dos cosméticos é necessário à realização de análises microbiológicas do produto, fase fundamental para se conseguir um padrão de qualidade. $\mathrm{Na}$ utilização pessoal de um cosmético como o batom, os microrganismos podem ser trazidos diretamente pelo próprio consumidor, visto que a pele possui uma microbiota natural. A transmissão involuntária de microrganismos ocasiona danos à saúde do consumista, considerando a contagem de fungos e bactérias existentes no produto (FELLINI; GALVAO; GARVIL, 2015; ROCHA, 2016).

Quando há indícios de contaminação por microrganismos no cosmético, diversos problemas podem ser ocasionados, como a ocorrência de patologias, de nível leve a grave, causando eventuais complicações à saúde do usuário (FELLINI; GALVAO; GARVIL, 2015).

Como o hábito do uso de maquiagem vem crescendo, o batom torna-se um item bastante consumido e compartilhado no dia-a-dia, sendo assim um possível item potencial de contaminação microbiológica e fonte de transmissão, acarretando problemas de saúde a seus usuários. Dessa forma, objetivou-se nesse trabalho verificar a presença de microrganismos patogênicos em batons de uso compartilhado.

\section{Material e Métodos}

\subsection{Desenho de Estudo}

Neste estudo foram realizadas análises microbiológicas seguindo a Farmacopeia brasileira $5^{\circ}$ edição de 2010 (BRASIL, 2010), através do produto de maquiagem batom, de uso compartilhado, utilizados como mostruários de teste em lojas de cosméticos, visando verificar a presença de microrganismos nesse tipo de cosmético, tomando como base a RDC 481/1999 (BRASIL, 1999) que estabelece a ausência de bactérias patogênicas em $1 \mathrm{~g}$ da amostra pesquisada. $\mathrm{O}$ estudo foi realizado no laboratório de microbiologia da Faculdade de
Medicina Estácio de Juazeiro do Norte, no período dos meses de outubro e novembro de 2017.

\subsection{Coleta das Amostras}

As oito amostras foram coletadas de forma aleatória em uma loja de varejo que foi selecionada por ser de grande circulação, na cidade de Juazeiro do Norte - Ceará, com todas as amostras dentro dos prazos de validades, a partir da retirada de $1 \mathrm{~g}$ dos batons de uso compartilhado, para análises microbiológicas com técnicas de diluição e cultura em placa de Petri por semeio em estrias simples, investigando a presença de bactérias patogênicas.

\subsection{Culturas e Linhagens Bacterianas}

\subsubsection{Identificação de bactérias Gram-negativas}

Preparo da amostra e pré-incubação: Preparou-se a amostra partindo de uma diluição $1: 10$ de $1 \mathrm{~g}$ do produto. Utilizou-se $1 \mathrm{ml}$ da diluição para $9 \mathrm{ml}$ de Caldo BHI (Infusão Cérebro coração), ou quantidade correspondente a $1 \mathrm{~g}$. Homogeneizouse e foi incubado a $37{ }^{\circ} \mathrm{C}$ durante 18 a 24 horas. Seleção e cultura: Foi agitado e transferido uma alça da suspensão para placa contendo Agar MacConkey (Sugestivo para Escherichia coli) ou Agar Cetrimida (Específico para Pseudomonas aeruginosa) e incubado a $37{ }^{\circ} \mathrm{C}$ durante o período de 18 a 72 horas (ANVISA, 2010). Após o crescimento foi feito uma avaliação macroscópica e uma coloração de Gram para visualização microscópica.

\subsubsection{Identificação de bactérias Gram-positivas}

Preparo da amostra e pré-incubação: Preparou-se a amostra partindo de uma diluição $1: 10$ de $1 \mathrm{~g}$ do produto. Utilizou-se $1 \mathrm{ml}$ da diluição para $9 \mathrm{ml}$ de Caldo BHI (Infusão Cérebro coração), ou quantidade correspondente a $1 \mathrm{~g}$. Homogeneizouse e foi incubado a $37{ }^{\circ} \mathrm{C}$ durante 18 a 24 horas. Seleção e cultura: Foi agitado e transferido uma alça da suspensão para placa contendo Agar Manitol salgado (Sugestivo para Staphylococcus aureus) a 7,5\% de $\mathrm{NaCl}$. Incubou-se a $37{ }^{\circ} \mathrm{C}$ durante o período de 18 - 72 horas (ANVISA, 2010). Após o crescimento foi feito o teste de catalase para confirmação de Staphylococcus aureus, uma avaliação macroscópica e uma coloração de Gram para visualização microscópica.

\section{Resultados e Discussão}

As oito amostras de uso compartilhado que foram utilizadas nesse estudo de pesquisa microbiológica estavam com as suas características organolépticas de cor, odor e aspecto normais, e com o seu conteúdo dentro dos prazos de validade. Todas foram organizadas pelas cores Rosa (1), Vermelho (2), Nude (3), Rosa (4), Vinho (5), Nude (6), Marrom (7) e Roxo (8). Os resultados sugestivos de crescimentos obtidos no caldo BHI e em cada Agar específico podem ser visualizados no Quadro 1. 
Quadro 1 - Resultados obtidos para as análises microbiológicas das amostras dos cosméticos batons em meios seletivos.

\begin{tabular}{|c|c|c|c|c|}
\hline Amostras & BHI & $\begin{array}{c}\text { Manitol } \\
\text { Salgado }\end{array}$ & Cetrimida & Macconkey \\
\hline $\begin{array}{c}\text { Amostra 1 } \\
\text { (Rosa) }\end{array}$ & + & $\begin{array}{c}\text { Staphylococcus } \\
\text { aureus }\end{array}$ & - & $\begin{array}{c}\text { Escherichia } \\
\text { coli }\end{array}$ \\
\hline $\begin{array}{c}\text { Amostra 2 } \\
\text { (Vermelho) }\end{array}$ & + & $\begin{array}{c}\text { Enterococcus } \\
\text { sp. }\end{array}$ & - & - \\
\hline $\begin{array}{c}\text { Amostra 3 } \\
\text { (Nude) }\end{array}$ & - & - & - & - \\
\hline $\begin{array}{c}\text { Amostra 4 } \\
\text { (Rosa) }\end{array}$ & + & $\begin{array}{c}\text { Enterococcus } \\
\text { sp. }\end{array}$ & - & - \\
\hline $\begin{array}{c}\text { Amostra 5 } \\
\text { (Vinho) }\end{array}$ & + & $\begin{array}{c}\text { Enterococcus } \\
\text { sp. }\end{array}$ & $\begin{array}{c}\text { Pseudomonas } \\
\text { aeruginosa }\end{array}$ & $\begin{array}{c}\text { Crescimento } \\
\text { identificação }\end{array}$ \\
\hline $\begin{array}{c}\text { Amostra 6 } \\
\text { (Nude) }\end{array}$ & + & - & - & $\begin{array}{c}\text { Escherichia } \\
\text { coli }\end{array}$ \\
\hline $\begin{array}{c}\text { Amostra 7 } \\
\text { (Marron) }\end{array}$ & + & - & $\begin{array}{c}\text { Pseudomonas } \\
\text { aeruginosa }\end{array}$ & $\begin{array}{c}\text { Crescimento } \\
\text { sem } \\
\text { identificação }\end{array}$ \\
\hline $\begin{array}{c}\text { Amostra 8 } \\
\text { (Roxo) }\end{array}$ & + & - & - & $\begin{array}{c}\text { Escherichia } \\
\text { coli }\end{array}$ \\
\hline
\end{tabular}

(- sem crescimento, + com crescimento)

Fonte: Dados da pesquisa.

Os testes realizados para reafirmar tais colônias foram o teste de Catalase, para $S$. aureus e coloração de Gram, dando enfoque também aos aspectos macroscópicos das colônias de bactérias encontradas, descritos no Quadro 2.

Quadro 2 - Análise microscópica das colônias bacterianas

\begin{tabular}{|c|c|c|}
\hline Bactéria & Morfologia & $\begin{array}{c}\text { Classificação } \\
\text { de Gram }\end{array}$ \\
\hline Staphylococcus aureus & Coco & Gram + \\
\hline Escherichia coli & Bacilo & Gram - \\
\hline Enterococcus sp. & Coco & Gram + \\
\hline Pseudomonas aeruginosa & Bacilo & Gram - \\
\hline
\end{tabular}

Fonte: Dados da pesquisa.

Na amostra 1 (Rosa) foi detectada a possível presença de Staphylococcus aureus no meio de cultura Manitol Salgado, e de Escherichia coli no meio de cultura MacConkey, ambos específicos para o crescimento de tais bacterias. As amostras 2 (Vermelho) e 4 (Rosa) apresentaram um crescimento sugestivo de Enterococcus sp. no Agar Manitol Salgado.

Skowron et al. (2017) concluíram com seu teste microbiológico que a contaminação de cosméticos que passaram da sua data de validade ou que foram utilizados por mais de uma pessoa são consideravelmente mais propícios a contaminações. A maioria dos microrganismos isolados nas suas amostras são potencialmente patogênicos como exemplo o Staphylococcus spp. O presente estudo utilizou apenas amostras que estavam dentro do prazo de validade e mesmo assim houve contaminação por bactérias diferentes, o que destaca o problema que esse uso compartilhado traz para a população.

A amostra 3 (Nude) não apresentou crescimento no tubo, na primeira etapa da análise, assim não prosseguiu na segunda etapa do experimento. Esta foi a única amostra das oito testadas que se apresentou adequada dentro dos parâmetros estabelecidos por lei que estabelece a ausência de bactérias patogênicas em $1 \mathrm{~g}$ da amostra. Na amostra 5 (Vinho) foi encontrado como resultado sugestivo a presença de Enterococcus sp. no Manitol Salgado, de Pseudomonas aeruginosa no Agar Cetrimida e um crescimento sem identificação no Agar MacConkey.

As amostras 6 (Nude) e 8 (Roxo) obtiveram crescimento de bactérias Gram-negativas, sugestivo para Escherichia coli no Agar MacConkey. Já a amostra 7 (Marron) apresentou crescimento de Pseudomonas aeruginosa no Agar Cetrimida conforme e um crescimento sem identificação no Agar MacConkey.

Em um estudo realizado por Benvenutti et al. (2016) no Brasil, na cidade de Curitiba - Paraná, onde foram analisadas 15 amostras de maquiagens de uso coletivo divididas entre pó faciais, batons, blush, máscara de cílios e sombras, obtevese como resultados contaminação de uma amostra de pó facial, uma de máscara para cílios e outra de sombra, todas se apresentaram em desacordo com a RDC 481/1999 (BRASIL, 1999) por estarem contaminadas por Staphylococcus aureus. $\mathrm{O}$ autor indicou nesses resultados que os sistemas conservantes utilizados nesses produtos não foram eficazes. Diferentemente deste estudo, esse trabalho teve presença maior de enterobactérias, o que pode estar relacionado com o manuseio e a falta de higienização desses batons.

Dadashi e Dehghanzadeh (2016) enfatizam no seu estudo que o índice de contaminação microbiana em cosméticos compartilhados é maior do que as taxas relatadas para cosméticos pessoais nas literaturas, aumentando assim o risco de se adquirir uma contaminação por bactérias patogênicas através do compartilhamento de kits de maquiagens em salões de beleza, confirmando nos seus resultados a presença de Escherichia coli, Pseudomonas e Staphylococcus.

No município de Sarandi - PR, Accacio e Almeida et al. (2017) analisaram 57 amostras de cosméticos, usando o produto de máscara para os cílios como objeto de pesquisa, coletando as amostras em 10 salões de beleza da referida cidade, onde dessa amostragem total, 10 resultaram em contaminações microbianas positivas para o contaminante Staphylococcus epidermidis, confirmando que medidas preventivas de não compartilhamento desses produtos devem ser adotadas para segurança dos usuários. Mota et al. (2014) frisaram que o compartilhamento de produtos de maquiagem não é indicado, pois a probabilidade de se contrair conjuntivites e herpes aumentam consideravelmente, proporcionando danos tanto a saúde como danos estéticos (BRASIL, 1999).

Tran e Hitchins (1994) pesquisaram o risco de se adquirir uma infecção por bactérias usando cosméticos compartilhados, onde 2.892 amostras de produtos de maquiagens utilizadas para teste foram coletadas de 171 estabelecimentos de varejo em todos os Estados Unidos, onde foi possível isolar patógenos oportunistas como Staphylococcus aureus e Pseudomonas aeruginosa. Com os resultados obtidos, os autores advertiram 
que fossem adotadas precauções para aumentar a segurança dos produtos cosméticos de uso comum, com o intuito de se estipular limites de tempo de utilização para os cosméticos que servem de teste de uso compartilhado e solicitar o uso de materiais de aplicadores e de amostragem descartáveis, evitando assim a amostragem com o uso das mãos, diminuindo o foco de contaminação.

Dawson e Reinhardt (1981) realizaram uma investigação experimental microbiológica através de 1.345 amostras do produto de sombras para olhos, expostas como mostruários em diversas lojas de vendas cosméticas em Atlanta. Os resultados evidenciaram proliferações de diversas colônias do gênero Staphylococcus, Acinetobacter e Bacillus, por exemplo. A presença de $S$. aureus foi encontrada em 2,3\% do percentual de $67 \%$ do total das contaminações descobertas. Com isso, os autores deduziram que a maior parte da contaminação provavelmente foi introduzida nos cosméticos pela frequente utilização de dedos e aplicadores de uso múltiplo.

Diante dos resultados expostos foi possível verificar que a maioria dos batons utilizados nessa análise estavam contaminados por bactérias potencialmente patogênicas, ressaltando também que três amostras (1, 5 e 7) tiveram crescimento em pelo menos dois meios de cultura diferentes. Esse nível de contaminação pode se tornar um possível problema de saúde pública, por ser um produto de venda livre e sem a orientação de um profissional capacitado para the auxiliar acerca do uso adequado de forma individual.

O crescimento da bactéria Enterococcus sp. foi um achado interessante, já que não fazia parte dos tópicos dessa pesquisa, porém seu crescimento evidenciou que várias colônias estão propícias a se proliferarem em batons de uso compartilhado. Assim, os resultados encontrados se mostraram de acordo com as evidências dos autores que investigaram sobre o uso compartilhado de cosméticos, demostrando o alto índice de contaminação que o usuário se expõe ao utilizá-los.

\section{Conclusão}

A partir dos resultados obtidos foi possível concluir que o índice de contaminação das amostras de batons utilizados de modo compartilhado é potencialmente preocupante, já que das 8 amostras analisadas apenas uma se mostrou dentro dos limites microbianos permitidos por lei. Com isso, intensifica-se a necessidade de medidas que impeçam o compartilhamento dos produtos cosméticos, como a implementação de aplicadores e amostras descartáveis de uso individual nas lojas de varejo, a utilização de pinceis unitários para cada cliente em salões de beleza e a necessidade de orientação de uso através de um profissional capacitado como o farmacêutico por exemplo, que alerte sobre o risco de contaminação que os usuários possam se expor nesse manuseio, além da importância de cada usuário ter seu próprio kit de maquiagem de uso pessoal e individual.

\section{Referências}

ABIHPEC. Panorama do setor de Higiene Pessoal, Perfumaria e Cosméticos. 2016. Disponível em: https://abihpec.org.br/ publicacao/panorama-do-setor-2016-2/. Acesso em: 27 set. 2020.

ALMEIDA, M. et al. Staphylococcus aureus. Mostra Cientifica em Biomedicina, 1, n. 1, 2017. Disponível em: http:// publicacoesacademicas.unicatolicaquixada.edu.br/index.php/ mostrabiomedicina/article/view/842/757. Acesso em: 30 set. 2020.

BRASIL. Ministério da Saúde. Agência Nacional de Vigilância Sanitária (ANVISA). Resolução de Diretoria Colegiada (RDC) $n^{\circ}$. 481, de 23 de setembro de 1999. Disponível em: http://bvsms.saude. gov.br/bvs/saudelegis/anvisa/1999/res0481_23_09_1999_rep.html

BRASIL. Farmacopeia Brasileira, volume 2 / Agência Nacional de Vigilância Sanitária. Brasília: Anvisa, 2010. 546p. Disponível em: http://portal.anvisa.gov.br/documents/33832/260079/5\%C $2 \% \mathrm{AA}+$ edi $\% \mathrm{C} 3 \% \mathrm{~A} 7 \% \mathrm{C} 3 \% \mathrm{~A} 3 \mathrm{o}+-+$ Volume+1/4c530f86-fe 83 4c4a-b907-6a96b5c2d2fc. Acesso em: 6 nov. 2020.

BENVENUTTI, A. D. S. et al. Avaliação da qualidade microbiológica de maquiagens de uso coletivo. Arq. Ciênc. Saúde UNIPAR, v.20, n.3, p.159-163, 2016. doi: 10.25110/arqsaude. v20i3.2016.5701.

BRANDÃO, R.; GOMES, A.; BATISTA, F.; BORBA, T. et al. Análise microbiológica de bases cosméticas faciais. Rev. Eletr. Fac. Montes Belos, v.8, n.1, p.1-9, 2015.

DADASHI, L.; DEHGHANZADEH, R. Investigating incidence of bacterial and fungal contamination in shared cosmetic kits available in the women beauty salons. Health Promot Perspect, v.6, n.3, p.159-163, 2016. doi: 10.15171/hpp.2016.25.

DAWSON, N.L.; REINHARDT, D. J. Microbial flora of in-use, display eye shadow testers and bacterial challenges of unused eye shadows. Appl. Environ. Microbiol., v.42, n. 2, p. 297-302, 1981.

FELLINI, B. P.; GALVAO, R. D.; GARVIL, M. P. Avaliação microbiana de bases cosméticas do Tipo Lanette. $e-R A C, \mathrm{v} .4, \mathrm{n}$. 1, p.1-11, 2015.

GALEMBECK, F.; CSORDAS, Y. Cosméticos: a química da beleza. Coordenação Central de Educação a Distância, 2011. Disponível em: http://old.agracadaquimica.com.br/quimica/ arealegal/outros/175.pdf.

MAEHATA, P. Presença de elementos metálicos em cosméticos labiais: investigação dos impactos na saúde e o descarte no meio ambiente. São Paulo: USP, 2016.

MOTA, D. F. et al. Cosméticos ação e reação. Rev. Interf. Saúde Hum. Tecnol., v.4, n. 4, p.1-5, 2014.

ROCHA, N. S. Análise de qualidade microbiológica e fisicoquímica de cremes hidratantes capilares comerciais em uso. Brasilia: UnB, 2016.

SÁ, E. R. P. Programa de monitoramento do teor de chumbo em batons comercializados no município do Rio de Janeiro: uma questão de saúde pública. Saúde. Com-Ciênc, n. 2, 2016.

SKOWRON, K. et al. Microbiological purity assessment of cosmetics used by one and several persons and cosmetics after their expiry date. Roczniki Państwowego Zakładu Higieny, v.68, n.2, 2017.

TAHAN, G. P. Correlação entre o uso de batom e a concentração de parabenos em mulheres expostas ao cosmético. Alfenas: Universidade Federal de Alfenas, 2015.

TRAN, T. T.; HITCHINS, A. D. Microbial survey of shared-use cosmetic test kits available to the public. J. Ind. Microbiol., v.13, n.6, p.389-391, 1994. doi: 10.1007/BF01577224. 